\title{
Multimodal Construction of Fear in Film
}

\section{T. Krysanova}

Lesya Ukrainka Eastern European National University, Lutsk, Ukraine

Corresponding author. E-mail: tetianakrysanova@gmail.com

Paper received 30.03.19; Accepted for publication 11.04.19.

\section{https://doi.org/10.31174/SEND-Ph2019-195VII59-08}

\begin{abstract}
The paper deals with semiotic issues of constructing fear in the multimodal discourse of film. We argue that the multimodal construction of fear is realized through the semiotic integration of verbal, non-verbal and cinematographic resources actualized by visual and acoustic modes. The means characteristic for each semiotic resource have been singled out. Filmic fear can be actualized by the combination of three semiotic resources - verbal, non-verbal and cinematographic or two semiotic resources - non-verbal and cinematographic. A case study analysis allows to elaborate convergent or divergent patterns of filmic fear according to the parameter of the emotive congruence.
\end{abstract}

Keywords: emotive meaning, fear, film, multimodal construction, semiotic system.

Introduction. This paper addresses multimodal and semiotic issues of constructing the emotion of fear in film. Fear is a basic emotion, a universal property of a person, characterized by a combination of biological and social nature. It is a negative emotional state, caused by a real or feasible action and is aimed at mobilizing the efforts to prevent the damage to the person. Biologic nature of fear is realized through the human defensive reaction to the danger for his/her health and well-being. The emotion of fear can range from an unpleasant feeling of anxiety to horror [6]. The variety of fear forms indicates its importance for humans. Fear and the degree of its intensity is manifested in the neurophysiological reactions of the person characterized by the tension of facial muscles, increased heart rate, rapid breathing, immobility. Cognitive abilities of a person experiencing fear deteriorate, he/she loses the ability to orientate in space [6], all actions are directed to get rid of danger. Although the neurobiological, psychological aspects of emotions have been thoroughly investigated the nature of filmic emotions and their multimodal character is one of the least-explored topics in the linguistics of film.

Film is a multimodal phenomenon marked with the dynamic nature that is realized through the integration of several semiotic systems employed to construct the filmic meaning. Different semiotic information is integrated in a single filmic semantic space at the levels of content and form. Film discourse is "scripted" and "constructed" [3] and can be conceptualised as "fictional/nonauthentic/scripted conversations held by fictional characters" [4, p. 43]. Film demonstrates features typifying real interactions, so it can be interpreted with workings of linguistic theories [4, p. 44].

In the "emotional landscape of the modern world" $[12$, p.1] film takes an important place as it is apt to construct characters' emotions and concurrently elicit emotions from the viewers. The ability of film to provide emotional experiences, as Ed Tan notes, is based on the film emotion scenarios [14] which reflect the cognitive, cultural and linguistic knowledge of film viewers and filmmakers Lisa Barret claims that the emotive meaning is constructed from person's sensory input and past experience that leads to the ability to prescribe actions [1,p. 31]. Filmic emotion is scripted according to the scriptwriter's intention and is constructed by actors and filmmakers through the ascribing of the emotive meaning to the cinematic sign taking into account filmmakers' and recipient's experience.

A brief review of publications on the subject. Multimodal accounts on filmic emotions comprise few linguistic issues on verbal and non-verbal representation of emotions, expressive potential of filmic emotions, syntagmatic and paradigmatic relations in the construction of filmic emotions etc. Dezheng Feng and Kay O'Halloran develop a cognitive and semiotic approach to the representation of eliciting conditions and expressions of characters' emotions [5]. Klaus Scherer and Heiner Ellgring [13] focus on filmic nonverbal resources and their prototypical configurations in the construction of emotions. Todd Oakley and Vera Tobin offer the cognitive insight into the meaning-making process of filmic narrative [10]. Derek Bousfield and Dan McIntyre analyze emotions via a combination of sociopragmatic and multimodal stylistic analysis [2]. Rose Ann Kozinski takes a corpus approach to the exploration of similarities and differences in the emotional tone of the film depending on the film genre [7]. Analyzing filmic emotions through the multiple perspective enhances understanding how communication in film is constructed and how the pragmatic influence on the viewer is realized.

The goal. The article aims to provide a comprehensive multimodal account of how the emotion of fear is represented in film and eleborate a semiotic approach for understanding the filmic construction of fear. In this paper, we examine how fear is constructed by actors and filmmakers according to the scriptwriter's intention - i.e. represented by verbal, nonverbal and cinematographic semiotic systems - and how the interaction between different semiotic systems takes place.

Materials and methods. The material of the analysis are episodes of actualizing the emotion of fear in American films Titanic and The Bodyguard. Titanic is an epic romance and disaster film, directed by James Cameron (starring Leonardo DiCaprio and Kate Winslet) about members of different social classes who fall in love aboard the ship during the ill-fated maiden voyage. The Bodyguard is a romantic thriller film, directed by Mick Jackson (starring Kevin Costner and Whitney Houston), that tells about a former Secret Service agent-turnedbodyguard who is hired to protect Whitney Houston's character, a music star, from an unknown stalker. 
To study the multimodal construction of the emotion of fear in film we use an integrated multimodal analysis of film discourse that enables to regard the emotion as "semiotic discursive construct designed by filmmakers" [5, p. 81]. In this paper we use the semiotic analysis in order to reveal the interrelation between verbal, non-verbal and cinematographic elements that serve to construct fear and the methods of intentional and pragmalinguistic analysis of situations of fear. The film script texts employed for the analysis allow to determine the emotion type intended by the scriptwriter and the way of its actualization.

Results and discussion. One of the most noteworthy sign interaction models that explains the semiotic process is the triadic model by $\mathrm{Ch}$. Pierce. According to it, the process of semiosis is a relationship between a sign or representamen, an object and an interpretant [11, p.179]. The classification of signs, built on the relationship between the sign and the referent (signifier and signified) contains three basic types of signs: icons, indexes and symbols.

The film semiotic systems involve combinations of three types of signs for constructing the emotive meaning. These signs are distinguished by the degree of conventionality: the highest degree of conventionality is characteristic for symbols, the slightest for indexes, since the index is closely related to the subject, and, accordingly, it is the least conventional. The icon in film reflects the physical properties of the referent - photographic images, sound and light effects simulating the real life. Indexes in film are based on the adjacency of the signifier and signified, that are connected through a cause and effect relationship. They can be actualized in film by non-verbal means - gestures, facial expressions, physiological manifestations - for instance, tears are the index of sadness, laughter - the index of joy, cry - the index of anger etc. Symbols are metaphorical and can replace a certain object in film, for instance, a bat in the shot is a symbol of death that is the cause of fear. The use of cinematographic means also has a symbolic character: the close-up of a person's face, the point of view technique, and the angle pan always convey the emotive meaning.

Filmic signs are conventional, intentional and unmotivated. The filmic sign is conventional and unmotivated as its meaning is mediated by the linguistic culture of a particular language community; it is arbitrary in relation to what it means in film without obvious connection to it. The intentionality of the filmic sign lies in the fact that it enables to identify the film author's intention and is subject to certain social conventions. Filmic signs contain iconic, indexical and symbolic features. Film music indicates the emotion, acting as the index and at the same time symbolizes it. The gesture, being the index, has the features of icons, as the non-verbal construction of the emotion is affected by the on-screen image. Verbal signs, having a symbolic character, can acquire the features of icons: for instance, the written text on the screen is the image.

Filmic signs form verbal, nonverbal, and cinematographic semiotic resources (systems) that jointly construct the filmic emotive meaning: the verbal semiotic resource is represented by the verbal language; the non-verbal semiotic resource includes gestures, facial expression, prosody, etc.; and the cinematographic semiotic resource includes the signs of the cinematographic nature. The combination and interaction of meanings produced by each semiotic resource promotes the construction of the common emotive meaning. Following G. Kress and T. van Leeuwen [8], who interpret semiotic resources and modes as socially and culturally determined means of expressing meanings in communication, we assume that, in film, the construction of emotive meaning is the result of the integration of three semiotic resources (systems). The semiotic resource, as T. van Leeuwen claims, is "the actions, materials and artifacts we use for communicative purposes, whether produced physiologically [...] or technologically together with the ways in which these resources can be organized" [9, p. 285].

Filmic emotive meaning is transmitted through two information channels or modes: acoustic and visual. The acoustic mode is represented by sound effects, music etc. while the visual mode is realized through the image. The verbal component is presented in both modes orally on the acoustic level and in writing on the visual one. These modes can be analyzed dynamically as their combination varies in time and space producing semantic sequences. Semiotic resources and modes are organized into a range of meaning-making semiotic systems and are associated with the sensory modality perceived by human senses.

Fear is the basic universal emotion [6] that indicates its significance for humans. The verbal semiotic resource of the construction of fear is represented by lexical means expressing, describing and naming fear and syntactic means. Lexical means expressing fear are vulgarisms, evaluative adjectives and adverbs, interjections etc. - Oh, Uhh, Ach, Ooh, Omigod, Goodness, Oh my God, Oh gee, filthy, damn etc.; lexical means that describe emotions convey the person's emotional attitude towards the situation - frightened, scared, afraid, terrified etc., and lexical means that name the emotion of fear-fear, dread, awe, anxiety etc.

Syntactically fear is constructed with the use of incomplete sentences, semantically irrelevant repetitions, increased number of pauses that convey indecision or hesitation, violations of the syntactic structure of phrases, elliptical constructions of various types, exclamatory sentences showing the state of the person's emotional tension. Utterances conveying the meaning of fear belong to the expressive pragmatic type, which aims to convey a certain psychological state of the speaker. The syntactic level is represented by subject-oriented utterances that convey the person's fear and object-oriented utterances that reflect the characteristics of the person's actions and describe their state. The exclamations of fear convey the stereotypical appeal to higher power, which is associated with the perception of danger. In example (1) fear is realized by the lexical unit afraid that describes the emotion, the subject-oriented utterance (I'm afraid) and pausation actualizing the state of hesitation.

(1) FLETCHER Then what? What are you afraid of?

Frank doesn't have the will to resist anymore. He lets his hand drop away from Fletcher.

FRANK I'm afraid... of not being there... [16].

The non-verbal resource of the construction of fear is represented by nonverbal means that reflect the physiological manifestations of the emotion as the visualization is aimed at enhancing the pragmatic effect. The manifes- 
tation of fear can occur in two main forms: asthenic and sthenic. The first manifests itself in the passive-defensive reaction: numbness, immobility, the second - in mobilizing opportunities for the prevention of danger. The most reliable and powerful filmic indicators of fear are mimic manifestations: trembling lips, shaking or twitching mouth, eyes are either wide open or, conversely, tightly compressed; eyes can be filled with tears. The face can also be immobile, changing the color into white, pale.Vegetative manifestations of fear in film are highly representative: the person has problems with the rhythm of breathing, he/she sweats. Phonic means also reflect the physiological processes peculiar for the person experiencing fear. The voice trembles, he/she whispers or becomes hoarse. In situations of danger, when the person realizes the need to act for the sake of salvation, the voice raises, passes on a piercing scream. Kinetic means reflect the sthenic form - a person shakes, makes sharp moves, becomes aggressive and the asthenic form of fear - a person can't move and is paralyzed with fear as in example (2).

(2) DAN (V.O.) \#eerily distorted\# Guess again, whore! Fuck you and fuck Miami. I'm coming for you. I know where you are and I'm coming for you...

\#Rachel is paralyzed by fear, unable to hang up the phone\#.[16].

Cinematographic resource of constructing the emotion of fear contains cinematographic means - close-up and extreme close up, point of view technique, pan shooting, angle shot, music and the light and shadow interplay that aim at reflecting the physiological manifestations of fear and creating an appalling atmosphere.

The ability of close-up and extreme close up to construct emotions is achieved through the focusing on details - on frightened eyes, hands shaking with terror, shivering lips etc. Close-up and extreme close up aim at the specification of the frightful emotion experienced by the film character. They provide an opportunity to look into the filmic character's inner world, capture the subtle nuances of fear. The pragmatic aim of the point of view technique consists in attracting viewers to experience the fear of the film character. By using the point of view technique, filmmakers give the viewers the opportunity to see the reality through the filmic character's eyes and let them experience the same emotions at the film time. Pan shooting provides an emotional epithet accounting for filmic events, as well as to the filmic character's behaviour or his/her psychological state. Pan shooting helps viewers realize the communicative situation and empasize the filmic character experiencing fear. Angle shot depicts the filmic character at an acute angle, focuses on the psycho-emotional state and intensifies the emotion of fear.

Film is highly metaphorical in nature that's why music having great symbolic potential is widely used to construct fear. It illustrates the collective panic, conveys the film character's state of fear, performs the function of the emotional commentary or marks the gradual increase or decrease of fear.

The expressiveness of the shot depends on the colour, brightness and saturation that is why the light plays a significant role in constructing fear. Chiaroscuro or light and shadow interplay is used to create distinct areas of light and darkness in films in order to construct the fearful atmosphere. Typical light employed by filmmakers to construct fear is dim or blue light, dusk, night. In the following episode (3) from the film Titanic Fabrizio is panicking to realize his inevitable death. Cinematographically fear is constructed with the use of close up of his face in agony and his point-of-view when he sees the withdrawing life boat that means his death by cold.

(3)@Close on Fabrizio@ \#As he floats, panting each breath agony. You see the spirit leave him\#.

@Fabrizio'sPOV@ \#Cal in slow motion, yelling and wielding the oar. A demon in a tuxedo. The image fades to black\#.[15].

The meaning of fear in film is constructed by the integration of different semiotic resources. The emotive meaning created by means of each semiotic resource overlaps and the combination of meanings constructs the common emotive meaning. Fear in film can be constructed by the combination of

a) three semiotic resources - verbal, non-verbal and cinematographic.

(4) RACHEL@close up@Itwasn'twhat he said... it was the way he said it... he was so..\#.Her voice cracks. She stops and tries to compose herself\#.

RACHEL I need you... I'm afraid... and I hate it. I hate myfear...@a beat@Please protect me...Protect Fletcher... If anything happened to him...

\#Frank looks at her. Tears are destroying her elaborate stage makeup. She wipes them away with her hand\#.[16].

In example (4) the verbal semiotic resource is represented by lexical units afraid, fear and elliptical sentences; the non-verbal semiotic resource - by phonic means and weeping; the cinematographic semiotic resource is represented by beat and Rachel's close up.

b) two semiotic resources - non-verbal and cinematographic, since image, or the visual mode, is inherent in film. In example (5) the image of panicking people is combined with the screams of horror and sharp loud music.

(5) AT THE STERN \#The propellers are 100 feet out of the water and rising. Panicking people leap from the poop deck rail, fall screaming and hit the water like mortar rounds. A man falls from the poop deck, hitting the bronze hub of the starboard propeller with a sickening smack\#.[15].

The emotive meanings created by means of different semiotic resources can coincide intensifying the common emotive meaning or contradict that leads to the weakening of the emotion. In accordance with the congruence of meanings constructed by semiotic resources we distinguish convergent or divergent patterns.

Convergent pattern occurs in case fear is constructed by semiotic resources that coincide in their emotive potential or their combination intensifies the emotion. In example (6) fear is constructed by the means of cinematographic and non-verbal semiotic resources. The passengers of Titanic shout in panic as the life boat is going to fall down on them. The sharp non-linear music and the light and shadow interplay intensify the emotive meaning.

(6) IN THE WATER BELOW \#There is another panic. Boat 13, already in the water but still attached to its falls, is pushed aft by the discharge water being pumped out of the ship. It winds up directly under boat 15, which is coming down right on top of it. The passengers shout in 
panic to the crew above to stop lowering. They are ignored. Some men put their hands up, trying futilely to keep the 5 tons of boat 15 from crushing them\#@nonlinear music, chiaroscuro @.[15].

Divergent pattern occurs when one semiotic resource contradicts the emotive meaning constructed by another that adds some shades to the emotive meaning.

(7) RACHEL Bill Devaney, ladies and gentlemen, thank you, Bill. Hey, everyone. Hello! Isn't Billy Thomas the greatest. He's asked me to sing a song. I hope you don't mind.

\#The crowd roars its approval. Frank nervously scans the room. Rachel smiles and moves along the stage. @MUSIC starts in the b.g@. Masking obvious fear, she starts to sing. As she takes one hand from the microphone, her fingers tremble. She clasps it again to hide her anxiety\#.[16].

Rachel fears to be attacked by the unknown criminal but she doesn't want to cancel the concert. The meaning of fear in example (7) is constructed non-verbally by trembling fingers. Energetic and enjoyable background music contradicts her fear and weakens the emotion.

Conclusions. Multimodal construction of filmic fear is realized through the semiotic integration of verbal, non- verbal and cinematographic resources actualized by visual and acoustic modes. The construction of the emotive meaning in film is the result of the interaction between the real world of filmmakers and the imaginary world of diegesis. The specificity of the film emotion of fear lies in its high expressive potential predetermined by the aesthetics of cinema. The construction of film fear can be realized in two ways: a) by the combination of three semiotic resources - verbal, non-verbal and cinematographic and b) two semiotic resources - non-verbal and cinematographic. According to the parameter of the congruence of emotive meanings of fear actualized by means of different semiotic resources, the filmic construction of fear can be convergent or divergent. Under the conditions of convergence, verbal, non-verbal and cinematographic semiotic resources simultaneously actualize identical emotive meanings. The divergence of heterogeneous semiotic means lies in the actualization of different emotive meanings that weakens the pragmatic influence of fear adding other emotive meanings. The perspectives of the multimodal study comprise the characteristics of constructing other basic negative emotions in English films.

\section{REFERENCES}

1. Barret, Lisa. (2017). How Emotions are Made. The Secret Life of the Brain. Boston, NY: Houghton.

2. Bousfield, Derek \& McIntyre, Dan. (2011). Emotion and Empathy in Martin Scorsese's Goodfellas // In: Piazza, Roberta; Bednarek. Monika \& Rossi. Fabio (eds.). Telecinematic Discourse Approaches to the Language of Films and Television Series, 105-123.

3. Chovanec, Jan. (2011). Humour in quasi-conversations: Constructing fun in online sports journalism // In: Dynel, Marta (ed.) The Pragmatics of Humour across Discourse Domains, 243-264.

4. Dynel, Marta. (2011). "Stranger than Fiction? A Few Methodological Notes on Linguistic Research in Film Discourse".// Brno Studies in English. 37 (1): 41-61. doi: 10.5817/BSE2011-1-3

5. Feng, Dezheng and O'Halloran, Kay L. (2013). The Multimodal Representation of Emotion in Film: Integrating Cognitive and Semiotic Approaches // Semiotica. 197: 79 - 100 doi: 10.1515/sem-2013-0082

6. Izard, Carrol E. (1991). The Psychology of Emotions. New York : Plenum.

7. Kozinski, Rose Ann. (2011). Quantifying the emotional tone of James Bond films // In: Piazza, Roberta; Bednarek. Monika \& Rossi. Fabio (eds.). Telecinematic Discourse Approaches to the Language of Films and Television Series, 125-140.

8. Kress, Gunther and van Leeuwen, Theo. ( 2006). Reading Images: The Grammar of Visual Design. London: Routledge.

9. Leeuwen van, Theo. (2004). Introducing Social Semiotics: An Introductory Textbook. London: Routledge.

10. Oakley, Todd and Tobin, Vera. (2012). Attention, Blending, and Suspense in Classic and Experimental Film // In: Schneider, Ralf and Hartner, Marcus (eds.). Blending and the Study of Narrative. Berlin: Mouton de Gruyter. 57-83.

11. Pierce, Charles. (2000) Nachala pragmatizma [The beginning of pragmatism]. Saint Petersburg : Laboratorija metafizicheskih issledovanij filosofskogo fakul'teta SPbGU. (in Russian).

12. Platinga, Carl and Smith, Greg M. (eds.). (1999). Passionate View: Film, Cognition and Emotion. Baltimore, London: The Johns Hopkins University Press.

13. Scherer, Klaus. R. and Ellgring, Heiner. (2007). Multimodal Expression of Emotion: Affect Programs or Componential Appraisal Patterns // Emotion. 7: 158-171.

14. Tan, Ed. (1999). Sentiment in Film Viewing // In: Platinga, Carl and Smith, Greg M. (eds.). Passionate View: Film, Cognition and Emotion. Baltimore, London: The Johns Hopkins University Press. 48-64.

15. Titanic. Available at: https://www.imsdb.com/scripts/Titanic.html

16. The Bodyguard. Available at: https://www.imsdb.com/scripts/Bodyguard.html 